\title{
Notas taxonômicas sobre o gênero Nitella C. Agardh (Characeae) da Região Metropolitana de Feira de Santana, Estado da Bahia, Brasil
}

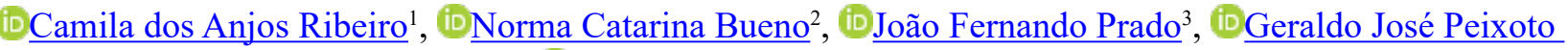 \\ $\underline{\text { Ramos }}^{1}$ e (iD Carlos Wallace do Nascimento Moura ${ }^{1,4}$
}

Como citar: Ribeiro, C.A., Bueno, N.C., Prado, J.F., Ramos, G.J.P. \& Moura, C.W.N. 2021. Notas taxonômicas sobre o gênero Nitella C. Agardh (Characeae) da Região Metropolitana de Feira de Santana, Estado da Bahia, Brasil. Hoehnea 48: e1132020. https://doi.org/10.1590/2236-8906-113/2020

ABSTRACT - (Taxonomic notes on genus Nitella C. Agardh (Characeae) from the Metropolitan Region of Feira de Santana, Bahia State, Brazil). From a floristic study of the Family Characeae in the Metropolitan Region of Feira de Santana, Bahia State, we detected four species of Nitella, of which two are new additions for that state: N. axillaris, and N. praelonga, the latter being, of rare occurrence in Brazil, reported for the first time for the northeastern Brazil. The materials were analyzed using photonic and scanning electron microscopy. For all these species we provide descriptions, information on habitat, geographic distribution in Brazil and taxonomic notes.

Keywords: algae, Caatinga, Charophyta, semiarid, taxonomy

RESUMO - (Notas taxonômicas sobre o gênero Nitella C. Agardh (Characeae) da Região Metropolitana de Feira de Santana, Estado da Bahia, Brasil). A partir de um estudo florístico da Família Characeae na Região Metropolitana de Feira de Santana, Estado da Bahia, detectamos quatro espécies de Nitella, das quais duas são adições para o Estado: N. axillaris e $N$. praelonga, esta última, de ocorrência rara no Brasil, relatada pela primeira vez para o Nordeste brasileiro. Os materiais foram analisados através de microscopia fotônica e eletrônica de varredura. Para todas essas espécies fornecemos descrições, informações sobre hábitat, distribuição geográfica no Brasil e notas taxonômicas

Palavras-chave: algas, Caatinga, Charophyta, semiárido, taxonomia

\section{Introdução}

O gênero Nitella C. Agardh é caracterizado por apresentar talos delicados, ecorticados, com ou sem impregnação por carbonato de cálcio; râmulos simples ou furcados, terminados em dáctilos que podem ser uni ou pluricelulares; órgãos reprodutivos emergindo das furcações dos râmulos, com glóbulos ocupando posição terminal e núculas, com raras exceções (Nitella inversa Imahori), em posição lateral, e com corônula formada por dez células, dispostas em dupla camada. Ocorre em todos os continentes, exceto na Antártica, em ambientes aquáticos neutros ou ácidos ( $\mathrm{pH} 4,6-7,0)$ e, mais raramente, em ambientes alcalinos (pH 7,0- 8,6) (Wood \& Imahori 1965).

Nitella possui aproximadamente 240 táxons aceitos (Guiry \& Guiry 2020). Morfologicamente, apresenta três subgêneros: Nitella, com dáctilos unicelulares e célula terminal similar à penúltima; Hyella, com dáctilos pluricelulares e a célula terminal similar à penúltima; e Tieffalenia, com dáctilos pluricelulares e as células terminais diferentes das penúltimas células (Wood \&
Imahori 1965, Sakayama et al 2004a, Sakayama 2008, Casanova 2009).

Estudos moleculares, baseados em marcadores plastidiais ( $r b c \mathrm{~L}, a t p \mathrm{~B}, p s a \mathrm{~B})$ e nuclear (ITS), corroboram os subgêneros Hyella e Tieffallenia como monofiléticos e o subgênero Nitella como sendo parafilético (Sakayama et al. 2002, 2004b, 2006, 2008).

No Brasil, o gênero apresenta uma ampla distribuição geográfica sendo melhor conhecido e estudado nas regiões sul e sudeste (Bueno \& Bicudo 2020, no prelo). Para a Bahia os registros de Nitella são escassos e restritos a três trabalhos: Wood \& Imahori (1965), que referiram a ocorrência de $N$. furcata var. mucronata f. oligospira (A. Braun) R.D.Wood (= N. oligospira A. Braun); Bicudo \& Yamaoka (1978), que citaram N. cernua A. Braun; e Bueno \& Bicudo (2020), que listaram N. oligospira, N. mucronata (A. Braun) Miquel e N. subglomerata A. Braun.

Com o objetivo conhecer a biodiversidade e distribuição de Charophyceae na Região Metropolitana de Feira de Santana, o presente trabalho relata o reencontro de $N$. mucronata e $N$. cernua no Estado, e registra duas

1. Universidade Estadual de Feira de Santana, Departamento de Ciências Biológicas, Programa de Pós-graduação em Botânica, Avenida Universitária, Km 3, BR-116, 44031-460 Feira de Santana, BA, Brasil

2. Universidade Estadual do Oeste do Paraná, Programa de Pós-graduação em Conservação e Manejo de Recursos Naturais, Rua Universitária 2019, Jardim Universitário, 85819-110 Cascavel, PR, Brasil

3. Universidade Federal do Rio Grande do Sul, Departamento de Botânica, Avenida Bento Gonçalves 9500, 91501-970 Porto Alegre, RS, Brasil

4. Autor para correspondência: wallace@uefs.br 
adições para a ficoflora baiana: $N$. axillaris A. Braun e $N$. praelonga A. Braun. Esta última, de ocorrência rara no Brasil, está sendo relatada pela primeira vez para o Nordeste brasileiro. Para todas essas espécies fornecemos descrições, informações sobre hábitat, distribuição geográfica no Brasil e notas taxonômicas.

\section{Material e métodos}

O material estudado foi coletado nos municípios de Anguera, Amélia Rodrigues, Conceição do Jacuípe, Feira de Santana, São Gonçalo dos Campos e Serra Preta, na Região Metropolitana de Feira Santana, Bahia (Figura 1), em janeiro, outubro e novembro de 2015 e janeiro e fevereiro de 2016.

A Região Metropolitana de Feira Santana está localizada numa área de transição entre uma zona úmida (remanescentes de pequenas manchas de Mata Atlântica) e semiárida (Caatinga), com predomínio desta última. O clima é quente e úmido com temperatura média anual de $24^{\circ} \mathrm{C}$, com estação seca no inverno e chuvas no verão (Almeida 1992) e pluviosidade média de $800 \mathrm{~mm} / \mathrm{ano}$ (Souza et al. 2017).

A coleta do material foi realizada através de arranque manual, com auxílio de rastelo ou através do lançamento de um gancho fixado a um cabo, nas margens de lagoas, tanques (pequena área escavada para retenção de água para consumo animal e humano) e córregos de água doce.

Foram mensurados parâmetros limnológicos nos habitats como temperatura, $\mathrm{pH}$, condutividade elétrica e sólidos totais dissolvidos usando uma sonda portátil multiparâmetro (Hanna HI98130), e o oxigênio dissolvido com sonda Instrutherm (MO-910).

Os caracteres vegetativos e reprodutivos foram analisados com estereomicroscópio (Leica S8AP0) e microscópio óptico (MO) (Olympus BX43). As microfotografias em MO foram obtidas com máquina fotográfica digital QIMAGING 5.0 acoplada ao microscópio utilizando software Image-Pro Premier 9.1.4.

Para o estudo dos oósporos em microscopia ótica (MO) e microscopia eletrônica de varredura (MEV), estes foram removidos da planta com auxílio de estiletes e transferidos para microtubos de centrifugação, tipo eppendorf, contendo álcool a 70\%. Para a análise em MO, o material foi clarificado com hipoclorito de sódio, lavado em água destilada e preparado sobre lâmina e lamínula. O protocolo de preparo dos oósporos para análise em MEV segue Ribeiro et al. (2018). A terminologia empregada para descrever os oósporos em MEV segue John \& Moore (1987) e Casanova (1991).

Todas as amostras estudadas estão depositadas no Herbário da Universidade Estadual de Feira de Santana (HUEFS).

\section{Lista do material examinado:}

BRASIL, BAHIA: Região Metropolitana de Feira de Santana, Município de Feira de Santana, $12^{\circ} 07^{\prime} 54,3^{\prime}$ S e 3900'39,9'W, 13-X-2015, C.A.Ribeiro \& C.W.N.Moura s.n. (HUEFS 225675)

BRASIL, BAHIA: Região Metropolitana de Feira de Santana, Município de Conceição do Jacuípe, $12^{\circ} 17$ '58, 8 ”S e $38^{\circ} 45^{\prime} 32,8^{\prime \prime}$ W, 19-II-2016, C.A.Ribeiro \& G.J.P.Ramos s.n. (HUEFS 225686)

BRASIL, BAHIA: Região Metropolitana de Feira de Santana, Município de Serra Preta, $12^{\circ} 10^{\prime} 46,8$ 'S e 39॰21'10,8'W, 27-XI-2015, C.A.Ribeiro, G.J.P.Ramos \& C.W.N.Moura s.n. (HUEFS 225680); Município de São Gonçalo dos Campos, 12²0’37'S e 3857'36,5'W, 22-I2015, C.A.Ribeiro \& G.J.P.Ramos s.n. (HUEFS 225681); Município de Conceição do Jacuípe, $12^{\circ} 17$ '58,8”S e 38 45'32,8’'W, 19-II-2016, C.A.Ribeiro \& G.J.P.Ramos s.n., (HUEFS 225685); Município de Anguera, 1207'11,3”S e 39¹3'19,9'W, 24-II-2016, C.A.Ribeiro \& G.J.P.Ramos s.n. (HUEFS 225693).

BRASIL, BAHIA: Região Metropolitana de Feira de Santana, Município de Amélia Rodrigues, 12²2'50,6”S e $38^{\circ} 47^{\prime} 20,6^{\prime \prime W}, 29-I-2016$, C.A.Ribeiro \& G.J.P.Ramos s.n, (HUEFS 225684)

\section{Resultados e Discussão}

O material coletado na Região Metropolitana de Feira de Santana revelou a ocorrência de quatro espécies de Nitella, duas pertencentes ao subgênero Nitella, Seção Ridellia ( $N$. cernua e $N$. praelonga) e duas ao subgênero Tiefallenia, N. mucronata (Seção Tiefallenia) e N. axillaris (Seção Perssoonia), das quais duas são novos registros para a ficoflora da Bahia, e podem ser identificadas pela chave de identificação para as espécies de Nitella C. Agardh

Chave de identificação para as espécies de Nitella C. Agardh da Região Metropolitana de Feira de Santana

1. Dáctilos 1 celulados

2. Plantas monoicas; oósporo com parede verrucosa em MEV .................................................................. N. praelonga

2. Plantas dioicas; oósporo com parede fibrosa em MEV ............................................................................... N. cernua

1. Dáctilos 2-3 celulados

3. Râmulos verticilados dimórficos; oósporo com parede imperfeitamente reticulada a reticulada em MEV .....

N. axillaris*

3. Râmulos verticilados monomórficos; oósporo com parede reticulada em MEV 


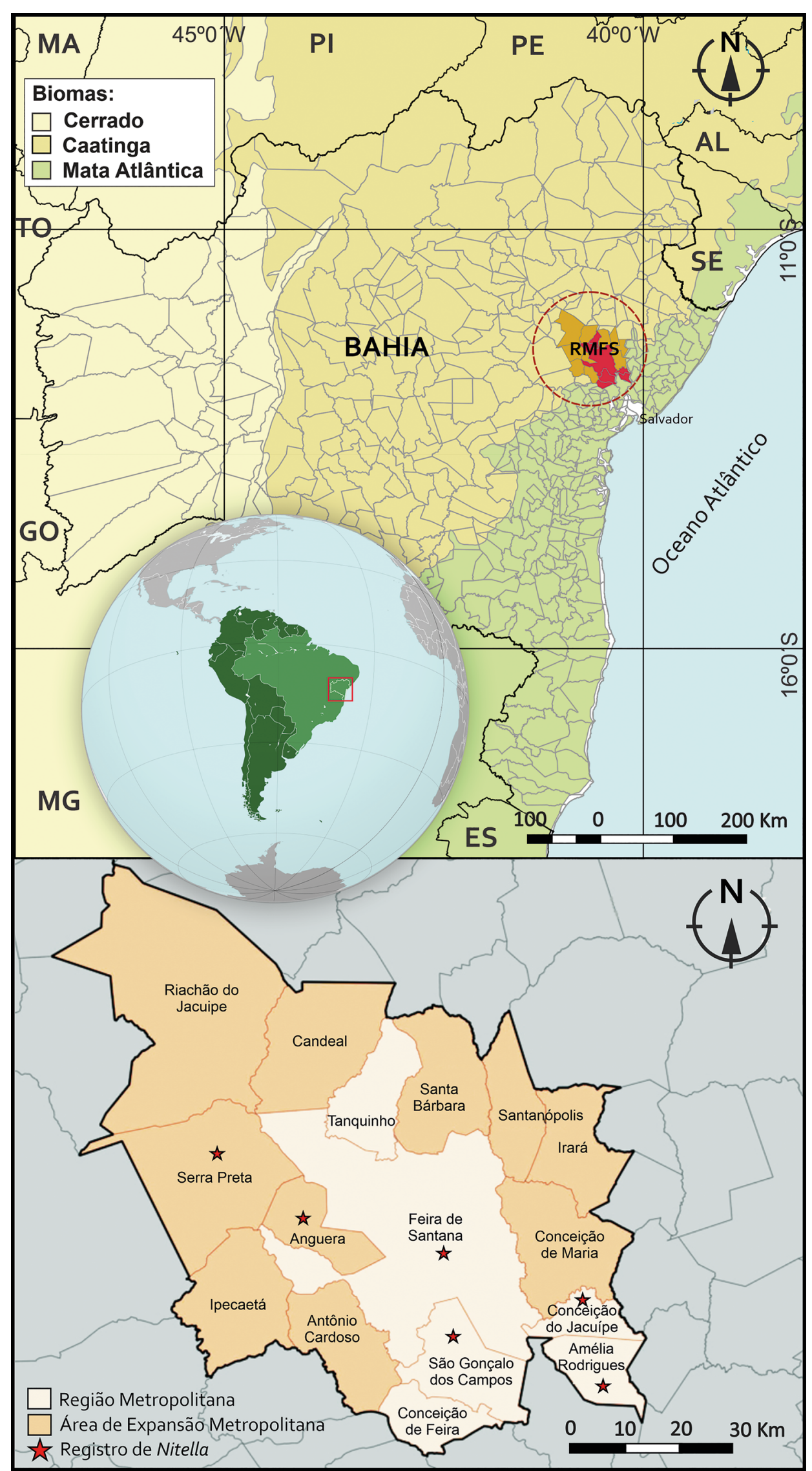

Figura 1. Mapa do Estado da Bahia, Brasil, destacando a localização dos municípios que fazem parte da Região Metropolitana de Feira de Santana (RMFS) e aqueles onde foram feitos registros de Nitella C. Agardh.

Figure 1. Map of the Bahia State, Brazil, highlighting the location of the municipalities from the Feira de Santana Metropolitan Region (RMFS) and those where Nitella C. Agardh has been found. 
1. Nitella axillaris A. Braun, Ber. Akad. Wiss. Berlin, 1858: 35.1858.

Figuras 2-3

Plantas monoicas, coloração verde clara, $10-20 \mathrm{~cm}$ compr., incrustação calcária ausente; cauloide 980-1288 $\mu \mathrm{m}$ diâm., entrenós 1,5-3 cm compr. Râmulos verticilados dimórficos, furcados, os estéreis longos e os férteis condensados em capítulos. Râmulos verticilados estéreis 7-8, 1-furcados, 1-2,9 cm compr., 736-935 $\mu \mathrm{m}$ diâm.; raios primários $7-8$, constituindo, praticamente todo o comprimento do râmulo; dáctilos 3-4, 1-celulados, ápices acuminados, 278-369 mm compr., 145-196 $\mu \mathrm{m}$ diâm. Râmulos verticilados férteis 7, 1-2 furcados, 1094-1372 mm compr., 112-131 $\mu \mathrm{m}$ diâm., condensados em capítulos; dáctilos 2-3, 2-celulados, ápices acuminados, 346-608 $\mu \mathrm{m}$ compr., 30-59 $\mu \mathrm{m}$ diâm. Capítulos axilares, condensados, numerosos, sem mucilagem, 2-6 por verticilo, 10-13 verticilos férteis.

Gametângios conjuntos, na base da $1^{\mathrm{a}}$ e $2^{\mathrm{a}}$ furcações; glóbulos 180-227 $\mu \mathrm{m}$ diâm., escudos 8, triangulares; núculas 1-2 por nó, 404-437 $\mu \mathrm{m}$ compr., 338-362 $\mu \mathrm{m}$ diâm., convoluções 7-8, corônula 16-25 $\mu \mathrm{m}$ compr., 44-53 $\mu \mathrm{m}$ diâm. Oósporo oval, amarelo, 6-7 estrias, 259-283 $\mu \mathrm{m}$ compr., 230-266 $\mu \mathrm{m}$ diâm., fossa 42-47 $\mu \mathrm{m}$ larg. Parede do oósporo em MO e MEV com padrão de ornamentação reticulado imperfeito (com cavidades de retículos fusionados) a reticulado (Figs $3 \mathrm{e}-\mathrm{g}$ ). As análises em MEV revelaram a presença de retículos com lúmens rasos, com diâmetros variados, até 4,7 $\mu \mathrm{m}$ diâm. quando fusionados, delimitados por cristas obtusas, estreitas, ca. 0,2 $\mu \mathrm{m}$ larg., além de estrias com ornamentação reticulada.

Material examinado: BRASIL. BAHIA. Região Metropolitana de Feira de Santana: Feira de Santana: HUEFS 225675.

Habitat: Plantas encontradas nas margens de tanque de fundo areno-lodoso, associadas a Salvinia $\mathrm{sp}$. Condutividade elétrica $0,17 \mathrm{mS} \mathrm{cm}^{-1}$; oxigênio dissolvido $14,3 \mathrm{mg} \mathrm{L}^{-1} ; \mathrm{pH}$ 8,02 ; sólidos totais dissolvidos 0,05 ; temperatura da água $26,3{ }^{\circ} \mathrm{C}$; temperatura do ar $28,8^{\circ} \mathrm{C}$.

Distribuição geográfica no Brasil: Pernambuco (Wood \& Imahori 1965, como Nitella translucens subsp. translucens var. axillaris), Mato Grosso do Sul (Bueno \& Bicudo 1997, como Nitella translucens subsp. translucens var. axillaris, Bueno et al. 2011), São Paulo (PicelliVicentim \& Bicudo 1993, como Nitella translucens subsp. translucens var. axillaris, Picelli-Vicentim et al. 2004, como Nitella translucens subsp. translucens var. axillaris), Paraná (Meurer \& Bueno 2012), Rio Grande do Sul (Prado 2003, como Nitella translucens subsp. translucens var. axillaris, Bueno et al. 2016), e Bahia (presente estudo).

Wood \& Imahori (1965), baseados na similaridade morfológica, como presença de râmulos férteis reunidos em pequenos capítulos, enquadraram $N$. axillaris como variedade de N. translucens (Pers.) C. Agardh.

Estudos realizados por Sakayama et al. (2002, 2004a, 2004b, 2008), utilizando marcadores moleculares (atpB, $r b c \mathrm{~L}, p s a \mathrm{~B}$, ITS) e ornamentação da parede do oósporo em MEV, demonstraram que $N$. translucens e $N$. axillaris eram espécies distintas, posicionadas em clados separados, $\operatorname{com} N$. axillaris mais relacionada à $N$. axilliformis Imahori.
Morfologicamente, Nitella axillaris lembra $N$. translucens, embora esta última possua diâmetro do caulóide e comprimento do oósporo maiores, com capítulos terminais e axilares (Picelli-Vicentim et al. 2004). Já a ornamentação da parede dos oósporos em MEV é nitidamente distinta entre estas, sendo rugosa em $N$. translucens e reticulada em N. axillaris (John \& Moore 1987, Sakayama et al. 2002).

Nitella axilliformis é morfologicamente próxima à $N$. axillaris, embora esta última seja distinta por apresentar capítulos muito pequenos, não ultrapassando $1 \mathrm{~mm}$. Sakayama (2008), baseado na análise de múltiplos marcadores moleculares (atpB, rbcL, psaB, ITS), considerou estas espécies distintas, corroborando as diferenças apontadas por Sakayama et al. (2004b) quanto à ornamentação reticulada do oósporo em $\mathrm{MEV}, \operatorname{com} N$. axillifomis exibindo cristas fundidas bem desenvolvidas e $N$. axillaris com cristas fundidas obtusas. Mais recentemente, Borge \& Necchi (2018), utilizando outros marcadores moleculares (rbcL, ITS1, ITS2), não encontraram distinção entre o material de $N$. axillaris do Brasil com amostras de $N$. axilliformis de outras regiões do mundo, sugerindo que esta poderia ser considerada sinônimo de $N$. axillaris.

No presente estudo, as dimensões e o padrão de ornamentação da parede do oósporo em MEV concordam com os descritos por Borge \& Necchi (2018) para plantas das regiões Centro-Oeste e Sudeste do Brasil, e com a ornamentação descrita por Sakayama et al. (2002) para espécimes do Japão.

Os espécimes estudados estão de acordo com as características vegetativas e reprodutivas, assim como as variações métricas apresentadas por Bueno \& Bicudo (1997), Prado (2003), Picelli-Vicentim et al. (2004), Bueno et al. (2011), Meurer \& Bueno (2012), Bueno et al. (2016) e Borge \& Necchi (2018).

O presente registro constitui-se na primeira citação da espécie para a Bahia.

2. Nitella cernua A. Braun, Ber. Akad. Wiss. Berlin, 1858: 354.1858

Figuras 4-6

Plantas dioicas, grandes, até $1 \mathrm{~m}$ compr., coloração verde claro a verde-escuro, incrustação calcária quando presente, aneliforme conferindo aspecto listrado à planta; cauloide 967,5 -2135 $\mu \mathrm{m}$ diâm.; entrenós 2,5-9 cm compr., 1,5 vezes mais longos do que os râmulos verticilados. Râmulos verticilados dimórficos; estéreis 6-8 por nó, 1-furcados, 1,8-4,5 cm compr., 715-2060 $\mu \mathrm{m}$ diâm.; raios primários 6-8, constituindo praticamente todo o comprimento do râmulo; dáctilos 3-6, 1-celulados, mucroniformes, 406-1116 $\mu \mathrm{m}$ compr., 101-567 $\mu \mathrm{m}$ diâm., geralmente formando uma pequena coroa no ápice do râmulo. Râmulos verticilados férteis 7-8, 1-furcados, dispostos em capítulos, envoltos por muco, 1005-1668 $\mu \mathrm{m}$ compr., 147-233 $\mu \mathrm{m}$ diâm.; dáctilos 3-4, 1-celulados, femininos largos com formato fusiforme, geralmente inflados na porção mediana 473-1000 $\mu \mathrm{m}$ compr., 112-206 $\mu \mathrm{m}$ diâm., masculinos pequenos, largos na base, 70-142,5 $\mu \mathrm{m}$ compr., 40-64 $\mu \mathrm{m}$ diâm. Capítulos frouxos, pequenos, 2-6 mm, terminais ou axilares, 2-4 por verticilo, cobertos com muco, pedunculados, pedúnculos de tamanhos 


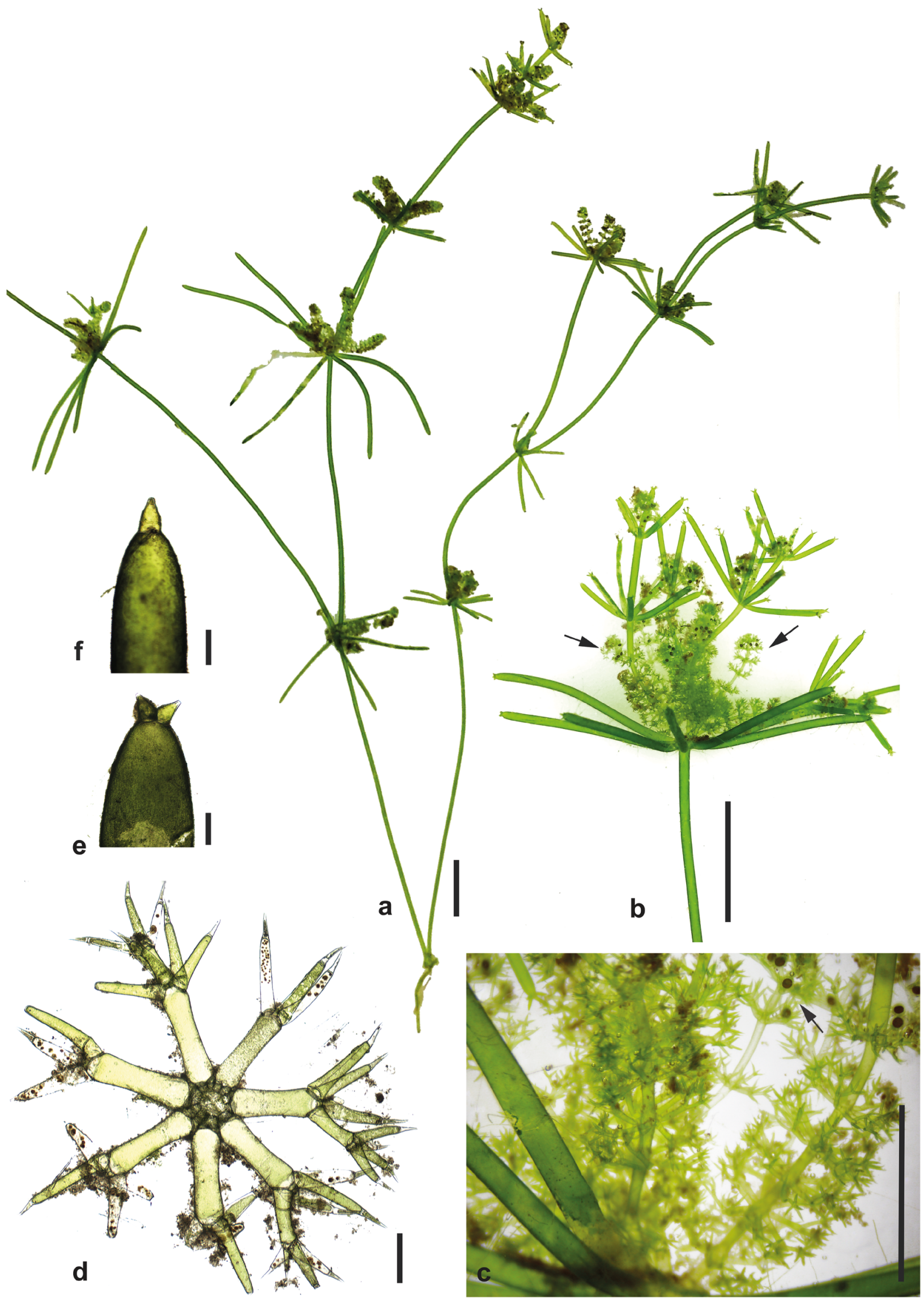

Figura 2. Nitella axillaris A. Braun. a. Hábito. b. Detalhe da porção apical da planta mostrando verticilos de râmulos estéreis 1-furcados e com capítulos axilares (setas). c. Detalhe dos verticilos de râmulos férteis dos capítulos, note oósporos (seta). d. Verticilo de râmulos férteis 1-2 furcados, portando dáctilos 2-celulados. e. Dáctilo estéril 2-celulados. Escalas: $\mathrm{a}-\mathrm{b}=1 \mathrm{~cm} ; \mathrm{c}=0,5 \mathrm{~cm} ; \mathrm{d}-\mathrm{e}=300 \mu \mathrm{m}$.

Figure 2. Nitella axillaris A. Braun. a. Habit. B. Detail of the apical portion of the plant showing whorls of sterile 1-furcated branches and with axillary heads (arrows). c. Detail of the whorls of fertile branches of the heads, note oospores (arrow). d. Whorl of fertile 1-2 furcated branches, carrying 2-celled dactyls. e. Sterile 2-celled dactyl. Scales: $a-b=1 \mathrm{~cm} ; \mathrm{c}=0.5 \mathrm{~cm} ; \mathrm{d}-\mathrm{e}=300 \mu \mathrm{m}$. 

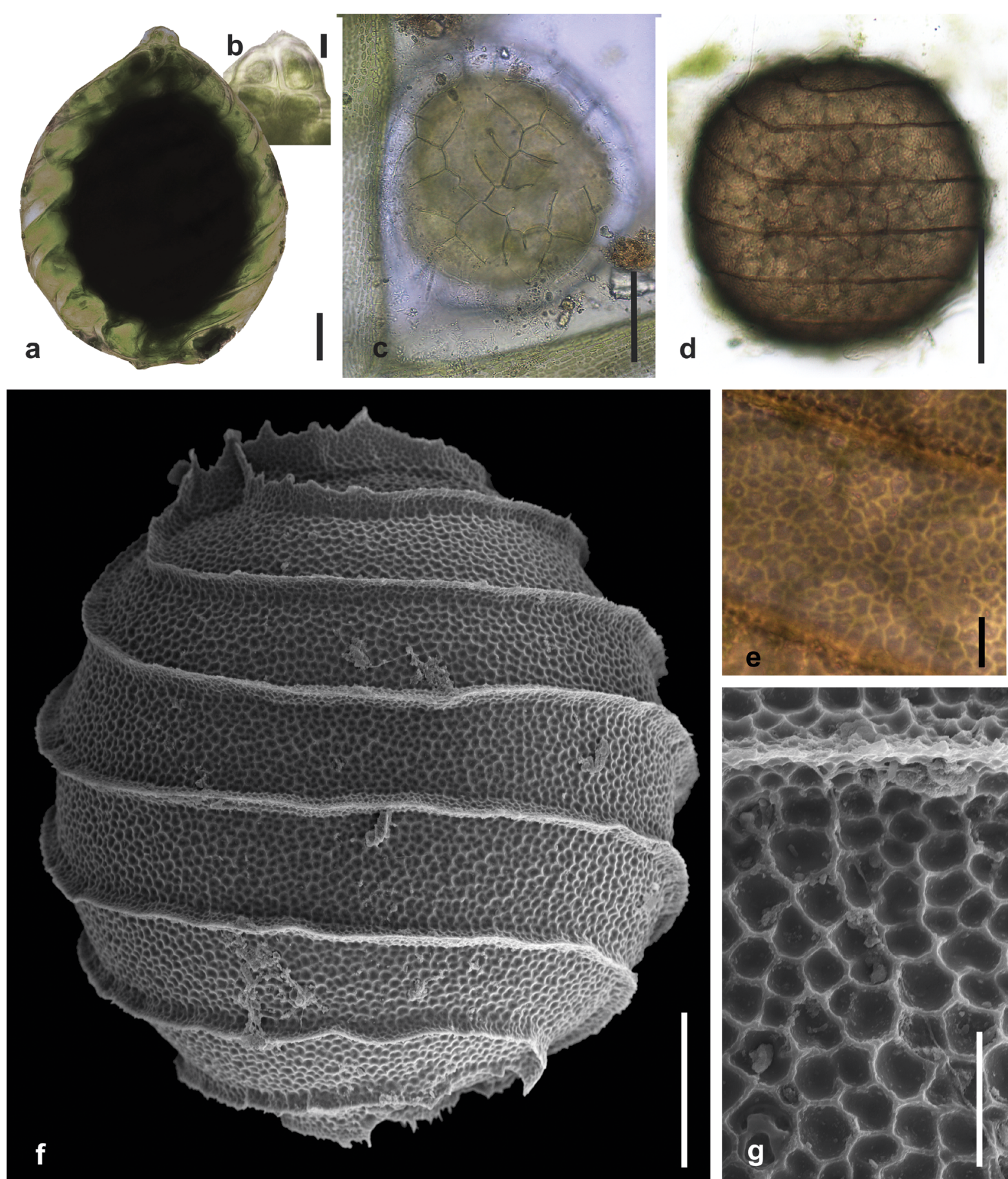

Figura 3. Nitella axillaris A. Braun. a. Núcula. b. Corônula. c. Glóbulo, note escudos triangulares. d. Oósporo visto em MO. e. Parede do oósporo com ornamentação reticulada imperfeita em MO. f. Oósporo visto em MEV, note parede reticulada imperfeita a reticulado. g. Detalhe da ornamentação reticulada irregular da parede do oósporo em MEV, note fusão entre cavidades do retículo. Escalas: b, e, $g$ $=10 \mu \mathrm{m} ; \mathrm{a}, \mathrm{d}, \mathrm{f}=60 \mu \mathrm{m}$.

Figure 3. Nitella axillaris A. Braun. a. Oogonium. B. Coronula. c. Antheridium, note triangular scutes. d. Oospore seen in LM. e. Oospore wall with imperfect reticulated ornamentation in LM. f. Oospore seen in SEM, note imperfect reticulated wall to reticulated. g. Detail of the irregular reticulated ornamentation of the oospore wall in SEM, note fusion between cavities of the reticulate ornamentation. Scales: b, e, $g=10 \mu \mathrm{m} ; \mathrm{a}, \mathrm{d}, \mathrm{f}=60 \mu \mathrm{m}$.

variados, 2-4 verticilos férteis, raios primários dos verticilos alongados conferindo aspecto umbeliforme.

Gametângios em plantas separadas; glóbulos 867-1042 $\mu \mathrm{m}$ diâm., 8 escudos, triangulares; núculas $2-5$ por nó, na base dos dáctilos, 495-685 $\mu \mathrm{m}$ compr., 444-637,5 $\mu \mathrm{m}$ diâm., convoluções 6-7, corônula 21-40 $\mu \mathrm{m}$ compr., 48-70,5 $\mu \mathrm{m}$ diâm., células superiores geralmente maiores. Oósporo oval, castanho-claro, 6-7 estrias, 435,5-476,4 $\mu \mathrm{m}$ compr., 421,7-495,9 um diâm., fossa 58,7-92,9 $\mu \mathrm{m}$ larg, estrias com borda saliente bem desenvolvida. Parede do oósporo difícil de ser visualizada em MO, geralmente opaca. Em MEV, parede com padrão fibroso (Fig. 6b), possuindo densa rede de fibrilas irregularmente anastomosadas, deixando espaços de tamanhos variados entre elas (0,3-1,6 $\mu \mathrm{m}$ diâm.) (Fig. 


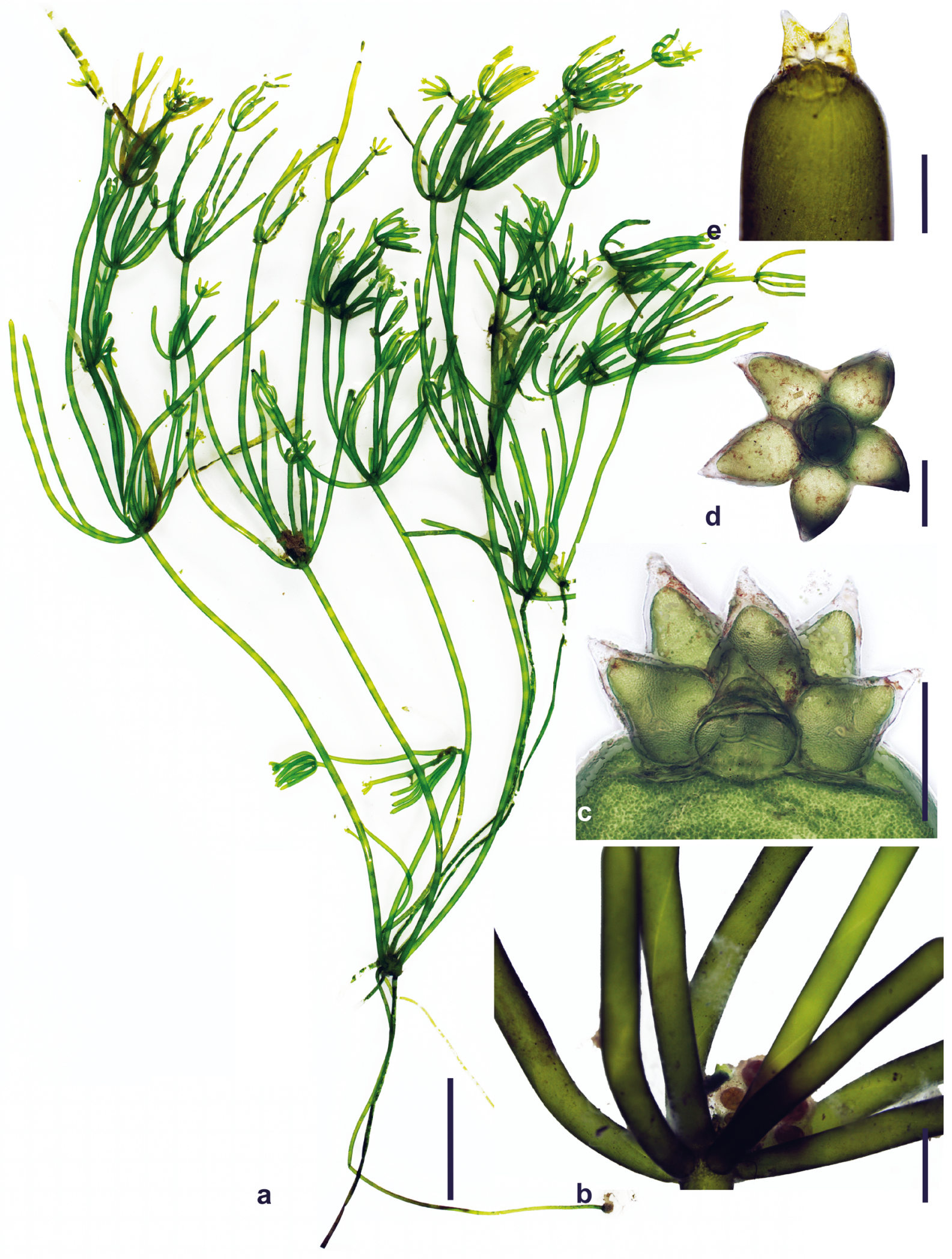

Figura 4. Nitella cernua A. Braun. a. Hábito. b. Verticilo de râmulos estéreis 1-furcados e capítulo axilar. c. Coroa de dáctilos estéreis mucroniformes 1-celulados. d. Vista apical da coroa de dáctilos. e. Dáctilos estéreis. Escalas: $\mathrm{a}=3 \mathrm{~cm} ; \mathrm{b}=1 \mathrm{~mm} ; \mathrm{c}-\mathrm{d}=250 \mu \mathrm{m} ; \mathrm{e}=0,5 \mathrm{~mm}$.

Figure 4. Nitella cernua A. Braun. a. Habit. b. Whorl of sterile 1-furcated branches and axillary head. c. Crown of sterile mucroniform 1-celled dactyls. d. Apical view of the dactyl crown. e. Sterile dactyls. Scales: $a=3 \mathrm{~cm} ; \mathrm{b}=1 \mathrm{~mm} ; \mathrm{c}-\mathrm{d}=250 \mu \mathrm{m} ; \mathrm{e}=0.5 \mathrm{~mm}$. 

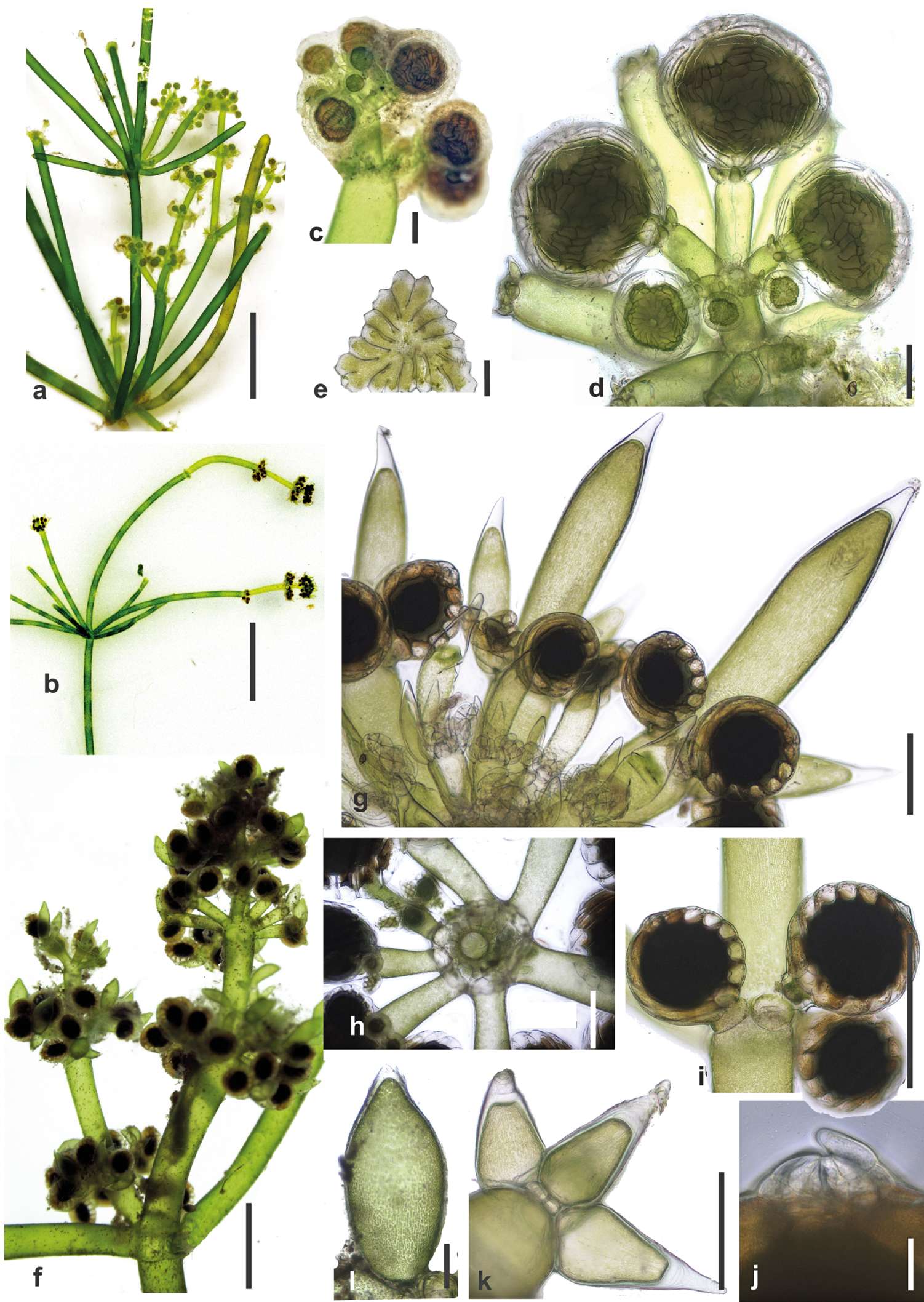

Figura 5. Nitella cernua A. Braun. a-b. Planta masculina com capítulos axilares e apicais. c. Capítulo de glóbulos. d. Glóbulos na base de dáctilos diminutos. e. Escudo triangular. f. Capítulos de núculas. g. Núculas na base de dáctilos inflados. h. Verticilo fértil com núculas. i. Núculas. j. Corônula. k. Dáctilos férteis inflados na base (plantas masculinas). 1. Dáctilos férteis inflados na porção mediana (plantas femininas). Escalas: $a-b=1 \mathrm{~cm} ; \mathrm{c}=0,5 \mathrm{~mm} ; \mathrm{e}, \mathrm{g}, \mathrm{i}, \mathrm{k}-\mathrm{l}=200 \mu \mathrm{m} ; \mathrm{d}, \mathrm{h}=300 \mu \mathrm{m} ; \mathrm{j}=30 \mu \mathrm{m}$.

Figure 5. Nitella cernua A. Braun. a-b. Male plant with axillary and apical heads. c. Head of antheridia. d. Antheridia on the basis of tiny dactyls. e. Triangular scute. f. Oogonia heads. g. Oogonia on the base of inflated dactyls. H. Fertile whorl with oogonia. i. Oogonia. j. Coronula. k. Fertile dactyls inflated at the base (male plants). 1. Fertile dactyls inflated in the median portion (female plants). Scales: $a-b$ $=1 \mathrm{~cm} ; \mathrm{c}=0.5 \mathrm{~mm} ; \mathrm{e}, \mathrm{g}, \mathrm{i}, \mathrm{k}-\mathrm{l}=200 \mu \mathrm{m} ; \mathrm{d}, \mathrm{h}=300 \mu \mathrm{m} ; \mathrm{j}=30 \mu \mathrm{m}$. 

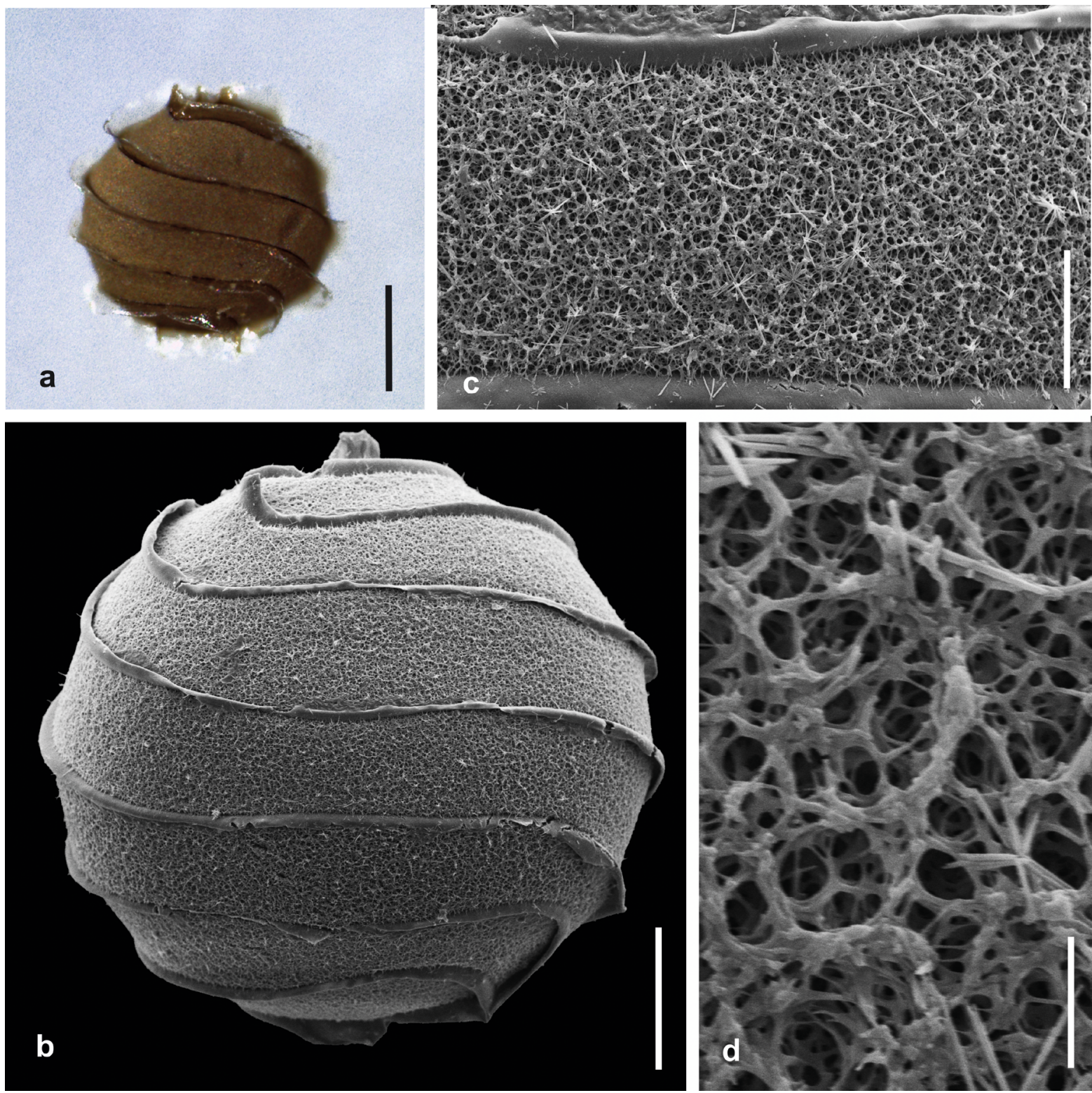

Figura 6. Nitella cernua A. Braun. a. Oósporo visto em MO, note estrias aladas. b. Oósporo visto em MEV. c. Detalhe da parede do oósporo em MEV, com padrão fibroso. d. Detalhe das fibras anastomosadas da parede do oósporo. Escalas: $\mathrm{a}=200 \mu \mathrm{m} ; \mathrm{b}=100 \mu \mathrm{m} ; \mathrm{c}$ $=30 \mu \mathrm{m} ; \mathrm{d}=5 \mu \mathrm{m}$.

Figure 6. Nitella cernua A. Braun. a. Oospore seen in LM, note winged striae. B. Oospore seen in SEM. c. Detail of the oospore wall in SEM, with fibrous pattern. d. Detail of the anastomosed fibers of the oospore wall. Scales: $a=200 \mu \mathrm{m} ; b=100 \mu \mathrm{m} ; c=30 \mu \mathrm{m} ; d=5 \mu \mathrm{m}$.

6c-d). Estrias sem ornamentação; vistas ao MO, as bordas são salientes; ao MEV, as saliências são reduzidas.

Material examinado: BRASIL. BAHIA. Região Metropolitana de Feira de Santana: Serra Preta: HUEFS 225680; São Gonçalo dos Campos: HUEFS 225681; Conceição do Jacuípe: HUEFS 225685; Anguera: HUEFS 225693.

Habitat: Encontrada crescendo nas margens de tanques de fundo argiloso, areno-argiloso e lodoso, com presença de Gramineae, Cyperaceae, Nymphaea sp., Spirogyra sp. Chara martiana Wallman, C. kenoyeri M.Howe e Nitella mucronata (A.Braun) Miq. Condutividade elétrica 0,8 ( \pm $\left.0,78 \mathrm{mS} \mathrm{cm}^{-1}\right)$; oxigênio dissolvido $10\left( \pm 0,72 \mathrm{mg} \mathrm{L}^{-1}\right)$; pH $8.2( \pm 1,21)$; sólidos totais dissolvidos $0,4( \pm 0,39)$; temperatura da água $28,4\left( \pm 3^{\circ} \mathrm{C}\right)$, temperatura do ar 26,4 $\left( \pm 1,81^{\circ} \mathrm{C}\right)$.
Distribuição geográfica no Brasil: Mato Grosso do Sul (Bueno \& Bicudo 1997), Minas Gerais (Wood \& Imahori 1965), São Paulo (Wood \& Imahori 1965, Bicudo \& Yamaoka 1978, Picelli-Vicentim 1990, Necchi-Junior et al. 2000, Vieira-Junior et al. 2002, Picelli-Vicentim et al. 2004), Pernambuco (Siqueira-Filho \& Bueno 2012), e Bahia (Bicudo \& Yamaoka 1978).

Morfologicamente, Nitella cernua é próxima à $N$. praelonga A. Braun e à Nitella translucens (Pers.) C. Agardh emend R.D.Wood. A primeira é distinta de $N$. cernua por ser monoica (Bicudo \& Yamaoka 1978, Bueno \& Bicudo 1997, Vieira-Junior et al. 2002, Picelli-Vicentim et al. 2004) e, a segunda, por possuir dáctilos 2 celulados, oósporos e glóbulos geralmente menores, e ausência de mucilagem nos capítulos (Wood \& Imahori 1965). 
O padrão de ornamentação da parede do oósporo dos espécimes de $N$. cernua analisados ao MEV apresentou padrão fibroso, concordando com os descritos por John \& Moore (1987), para material coletado no município de Corinto, Minas Gerais, tombados no Herbário do British Museum (BM, col. Ynes Mexia no 5602). Esse padrão pode ser empregado na separação de $N$. translucens, que apresenta parede rugosa, com rugas dispostas paralelamente entre si, mas não fibrosa (John \& Moore 1987) e de $N$. praelonga, que apresenta parede granulada (fig. $10 \mathrm{~h}, \mathrm{i}$ ).

Os espécimes estudados apresentaram caracteres similares aos descritos por Wood \& Imahori $(1964,1965)$, Bicudo \& Yamaoka (1978), Bueno \& Bicudo (1997), VieiraJúnior et al. (2002) e Picelli-Vicentim et al. (2004).

3. Nitella mucronata (A. Braun) Miquel in H.C. van Hall, Flora Belgii Septentrionalis 2: 428. 1840.

Figuras 7-8

Basiônimo: Chara mucronata A.Braun, Ann. Sci. Nat. Bot., ser. 2, 1: 351. 1834.

Plantas monoicas, 9-15 cm compr., incrustação calcária ausente; cauloide 317-504 $\mu \mathrm{m}$ diâm.; entrenós basais mais longos do que os râmulos, 0,3-1,2 cm compr. Râmulos verticilados furcados, monomórficos. Râmulos verticilados estéreis e férteis iguais 6, 2-3 furcados, 0,5-0,7 cm compr., 218-275 $\mu \mathrm{m}$ diâm.; raios primários 6-7, 2-4 mm compr., 105-188 $\mu \mathrm{m}$ diâm., raios secundários 4-6, raios terciários 2-4; dáctilos 2-4, 2 celulados, ápice acuminado, 298-1122 $\mu \mathrm{m}$ compr., 61-122 $\mu \mathrm{m}$ diâm.

Gametângios conjuntos e sejuntos, na base da 1'-2 a -furcação; glóbulos 193-312 $\mu \mathrm{m}$ diâm., escudos 8, triangulares; núculas 1 por nó, 222-445 $\mu \mathrm{m}$ compr., 183-

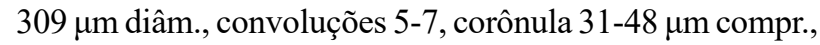
42-65 $\mu \mathrm{m}$ diâm., células superiores maiores. Oósporo oval, amarelo, 5-7 estrias, 253-264 $\mu \mathrm{m}$ compr., 203-257 $\mu \mathrm{m}$ diâm., fossa 36-55 $\mu \mathrm{m}$ larg. Parede do oósporo em MO e em MEV com padrão de ornamentação reticulado (Fig. 8ef). Em MEV, parede exibe retículos rasos (Fig. 8g), 2,4-3,7 $\mu \mathrm{m}$ diâm., com o lúmen delimitado por cristas estreitas (ca. 0,2 $\mu \mathrm{m}$ larg.), com elevações nos pontos de interseção (Fig. 8h). Estria similar à da fossa; borda reduzida ou ausente em MEV, provavelmente devido ao processo de limpeza, porém saliente em MO (Fig. 8d).

Material examinado: BRASIL, BAHIA: Região Metropolitana de Feira de Santana: Conceição do Jacuípe: HUEFS 225686

Habitat: Plantas encontradas crescendo na margem de tanque de fundo argiloso, associados à Nitella cernua, Chara martiana e $C$. kenoyeri. Condutividade elétrica $0,23 \mathrm{mS} \mathrm{cm}^{-1}$; oxigênio dissolvido 8,0 $\mathrm{mg} \mathrm{L}^{-1}$; $\mathrm{pH} 7,55$; sólidos totais dissolvidos 0,11 ; temperatura da água 31,1 ${ }^{\circ} \mathrm{C}$; temperatura do ar $30,6^{\circ} \mathrm{C}$.

Distribuição geográfica no Brasil: Ceará (Wood \& Imahori 1965), Bahia (Bueno et al. 2015), Minas Gerais (Necchi-Junior et al. 2008), Mato Grosso (Bueno et al. 2011), Mato Grosso do Sul (Bueno \& Bicudo 1997, como Nitella furcata subsp. mucronata (A. Braun) R.D. Wood, Bueno et al. 2011), Rio de Janeiro (Necchi-Junior et al.
2008), São Paulo (Necchi-Junior et al. 2000, Vieira-Junior et al. 2002, Picelli-Vicentim et al. 2004, como Nitella furcata subsp. mucronata, Branco \& Necchi-Junior 1998), e Rio Grande do Sul (Bueno et al. 2016).

Nitella mucronata foi facilmente diferenciada dos demais táxons inventariados na Região Metropolitana de Feira de Santana por apresentar dáctilos predominantemente alongados, 2 celulados com célula terminal mucronada, ausência de raio secundário central, gametângios presentes na primeira furcação e oósporo com padrão de ornamentação reticulado.

A espécie é morfologicamente semelhante à $N$. flagellifera e à $N$. furcata. A primeira difere por possuir raio secundário central e ausência de gametângios na primeira furcação, e a segunda, por apresentar dáctilos predominantemente abreviados e 2-3 celulados.

De acordo com Migula (1897) e Allen (1928), $N$. mucronata apresenta amplo polimorfismo; as variações presentes nessa espécie foram consideradas por Wood \& Imahori (1965) como formas de N. furcata subsp. mucronata. Posteriormente, Casanova (2009) e Sakayama (2008) mencionaram que a classificação de Wood \& Imahori (1965) foi baseada em conceito errôneo de espécie. Baseado nisso, o presente estudo considerou o táxon como espécie distinta e não como subespécie de $N$. furcata.

As observações da parede do oósporo, realizadas em MO e MEV, revelaram padrão de ornamentação reticulado. Em MEV, os oósporos apresentaram retículos rasos, com elevações nos pontos de interseção, não sendo possível visualizar tal característica em MO. Muito provavelmente, os oósporos analisados eram imaturos (cor clara, Fig. 8d), ou seja, com a ornamentação da parede ainda em formação. Segundo John \& Moore (1987), a ornamentação de oósporos só é confiável quando estes estão totalmente maduros (de cor escura, quase negra).

O padrão de ornamentação reticulado do oósporo em N. mucronata em MEV concorda com o descrito por Mandal et al. (1995) para espécimes da Índia, que relataram retículos estreitos e pouco elevados no ponto de intersecção. Esse padrão reticulado é referido por John \& Moore (1987) para material das Ilhas Britânicas e da África do Sul, e por Urbaniak (2009) para plantas da Polônia.

As plantas ora estudadas, concordam com as descrições e ilustrações de outros estudos realizados no Brasil (Bueno \& Bicudo 1997, Vieira-Junior et al. 2002, Picelli-Vicentim et al. 2004, Bueno et al. 2011, 2016).

4. Nitella praelonga A.Braun in A. Braun \& C.F.O.Nordstedt, Abh. Konigl. Akad. Wiss. Berlin 1882: 40. 1882.

Figuras 9-10

Plantas monoicas, até $30 \mathrm{~cm}$ compr., coloração verdeclaro a verde-escuro, incrustação calcária ausente; cauloide 602-976 $\mu \mathrm{m}$ diâm.; entrenós 2,5-5 cm compr. Râmulos verticilados dimórficos, furcados, estéreis longos e os férteis condensados em capítulos. Râmulos verticilados estéreis 6-7 por nó, 1-furcados, 1,5-2,2 cm compr., 446-498 $\mu \mathrm{m}$ diâm.; raios primários $6-7$, constituindo praticamente 


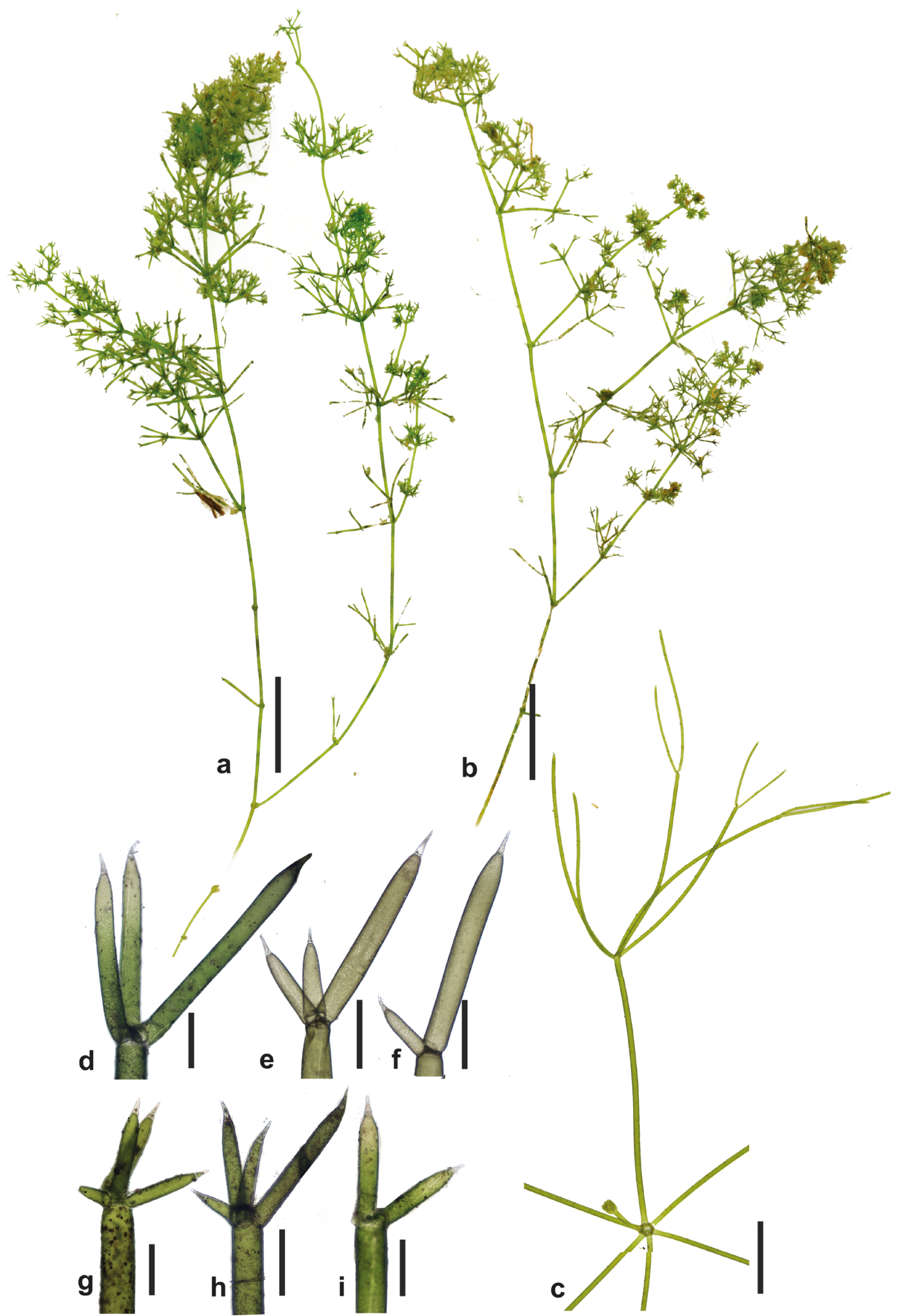

Figura 7. Nitella mucronata (A. Braun) Miquel. a-b. Hábito. c. Verticilo de râmulos estéreis 1-2 furcados. d-i. Dáctilos 2-celulados. Escalas: $\mathrm{a}-\mathrm{b}=1 \mathrm{~cm} ; \mathrm{c}=2 \mathrm{~mm} ; \mathrm{d}-\mathrm{i}=300 \mu \mathrm{m}$.

Figure 7. Nitella mucronata (A. Braun) Miquel in H.C. van Hall. a-b. Habit. c. Whorl of sterile 1-2 perforated branches. d-i. Two-celled dactyls. Scales: $\mathrm{a}-\mathrm{b}=1 \mathrm{~cm} ; \mathrm{c}=2 \mathrm{~mm} ; \mathrm{d}-\mathrm{i}=300 \mu \mathrm{m}$. 


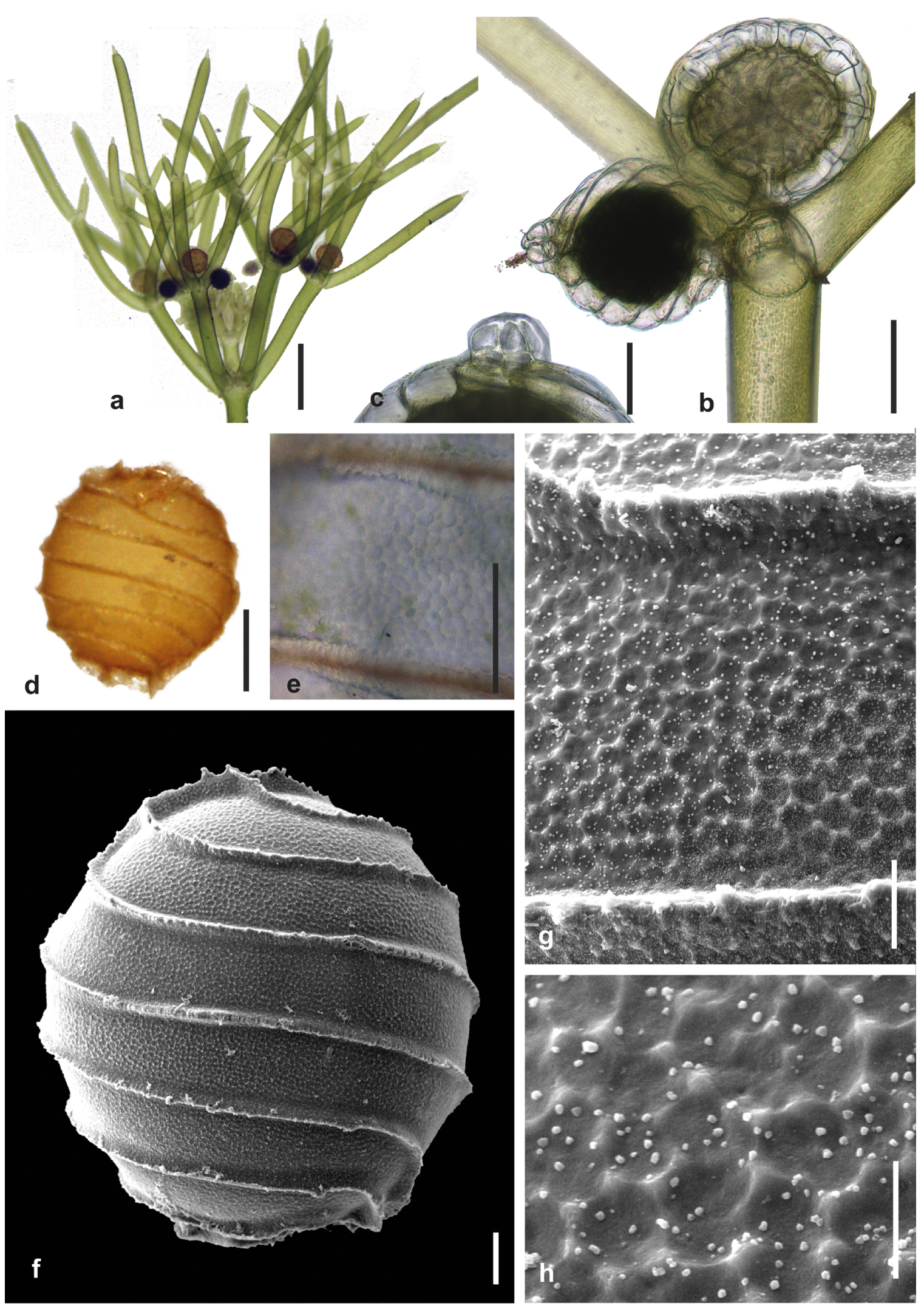

Figura 8. Nitella mucronata (A. Braun) Miquel. a. Verticilos com râmulos férteis jovens. b. Gametângios conjuntos. c. Corônula. d. Oósporo visto em MO. e. Detalhe da parede do oósporo visto em MO com padrão reticulado. f. Oósporo em MEV. g. Parede do oósporo em MEV com padrão reticulado. h. Detalhe do retículo com elevações nas interseções. Escalas: $a=500 \mu \mathrm{m} ; \mathrm{b}, \mathrm{d}=100 \mu \mathrm{m} ; \mathrm{c}=60 \mu \mathrm{m}$; $\mathrm{e}-\mathrm{f}=30 \mu \mathrm{m} ; \mathrm{g}=10 \mu \mathrm{m} ; \mathrm{h}=5 \mu \mathrm{m}$.

Figure 8. Nitella mucronata (A. Braun) Miquel. a. Whorls with young fertile branches. B. Conjoined gametangia. c. Coronula. d. Oospore seen in LM. e. Detail of the oospore wall seen in LM with a reticulated pattern. f. Oospore in SEM. g. Oospore wall in SEM with reticulated pattern. h. Detail of the reticulate ornamentation with elevations at the intersections. Scales: $a=500 \mu \mathrm{m} ; \mathrm{b}, \mathrm{d}=100 \mu \mathrm{m} ; \mathrm{c}=60 \mu \mathrm{m}$; e-f $=30 \mu \mathrm{m} ; \mathrm{g}=10 \mu \mathrm{m} ; \mathrm{h}=5 \mu \mathrm{m}$. 


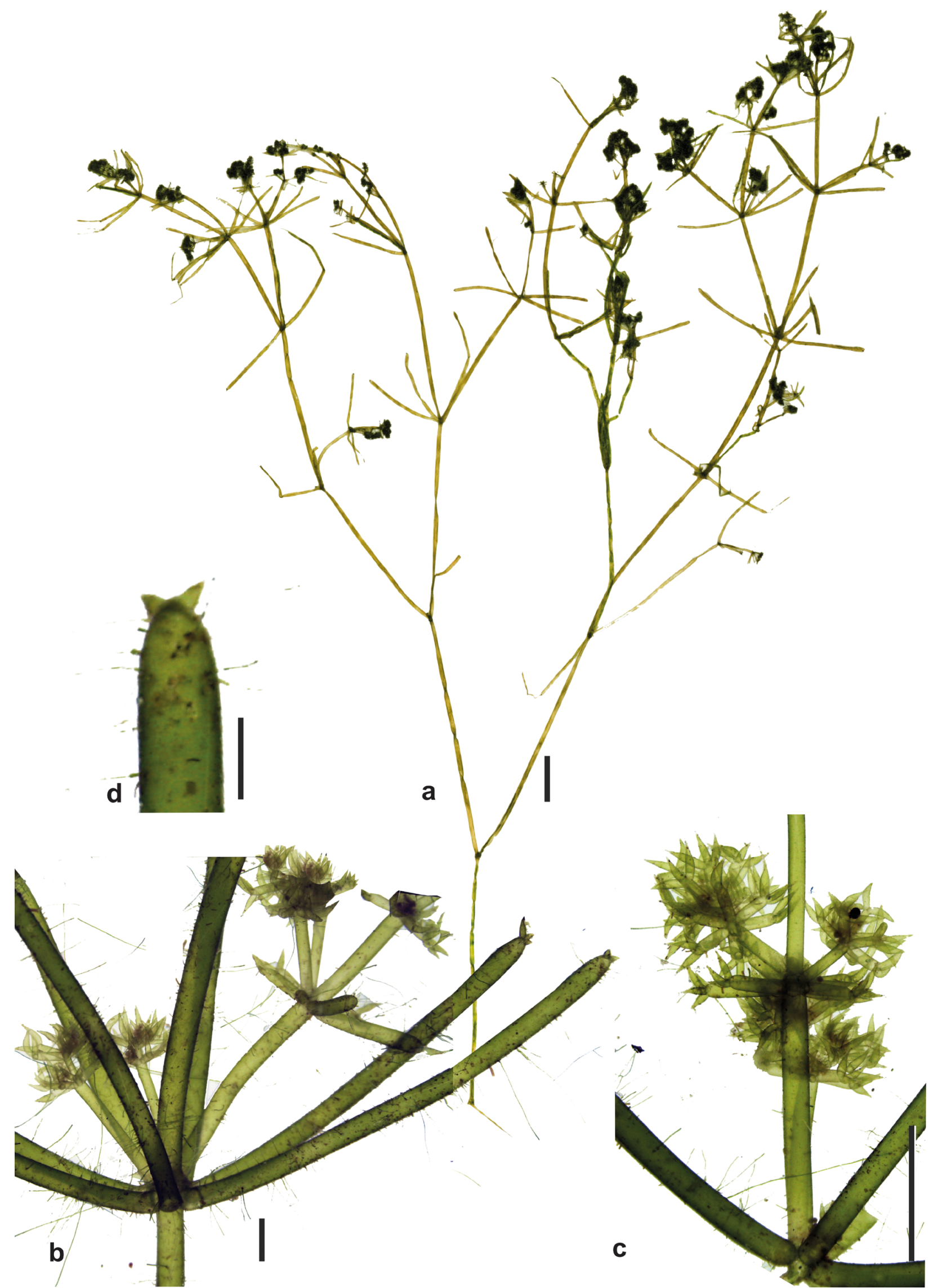

Figura 9. Nitella praelonga A. Braun. a. Hábito. b. Verticilo de râmulos estéreis, note capítulos axilares. c. Detalhe dos capítulos axilares. d. Dáctilo estéril 1-celulado. Escala: $\mathrm{a}=1 \mathrm{~cm} ; \mathrm{b}=1 \mathrm{~mm} ; \mathrm{c}=500 \mu \mathrm{m} ; \mathrm{d}=100 \mu \mathrm{m}$.

Figure 9. Nitella praelonga A. Braun. a. Habit. B. Whorl of sterile branches, note axillary heads. c. Detail of the axillary heads. d. Sterile 1-celled dactyl. Scale: $\mathrm{a}=1 \mathrm{~cm} ; \mathrm{b}=1 \mathrm{~mm} ; \mathrm{c}=500 \mu \mathrm{m} ; \mathrm{d}=100 \mu \mathrm{m}$. 


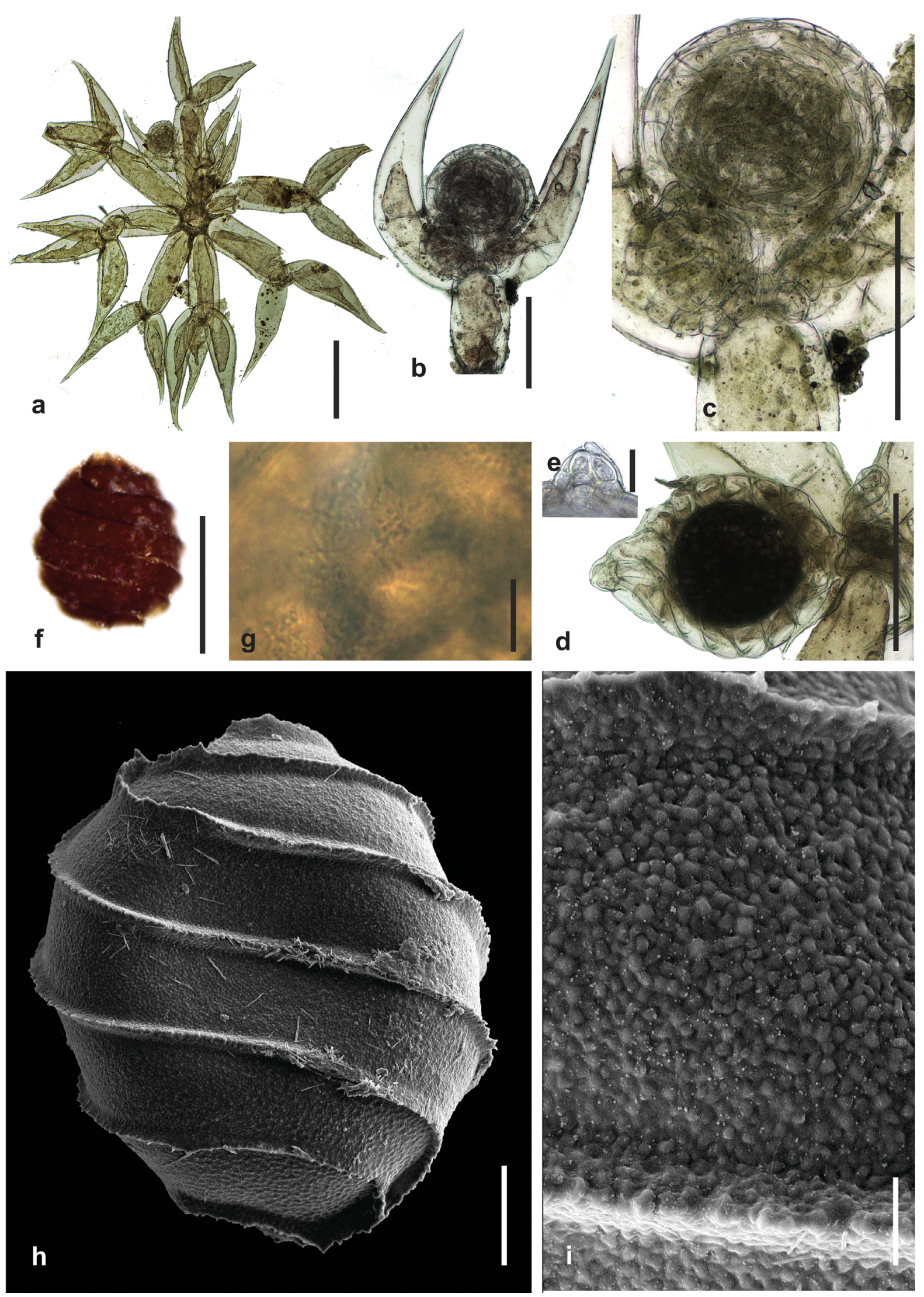

Figura 10. Nitella praelonga A. Braun. a. Verticilo de râmulos férteis 1-furcados com dáctilos 1-celulados inflados. b-c. Gametângios conjuntos, note núculas jovens (setas). d. Núcula madura. e. Corônula. f. Oósporo visto em MO. g. Detalhe da parede do oósporo em MO com padrão verrucoso. h. Oósporo em MEV. i. Parede do oósporo em MEV com padrão verrucoso. Escalas: $a=500 \mu \mathrm{m} ; \mathrm{d}, \mathrm{f}=200$ $\mu \mathrm{m} ; \mathrm{e}=30 \mu \mathrm{m} ; \mathrm{g}, \mathrm{i}=10 \mu \mathrm{m} ; \mathrm{h}=50 \mu \mathrm{m}$.

Figure 10. Nitella praelonga A. Braun. a. Whorls of fertile 1-furcated branches with inflated 1-celled dactyls. b-c. Conjoined gametangia, note young oogonia (arrows). d. Mature oogonium. e. Coronula. f. Oospore seen in LM. g. Detail of the oospore wall in LM with verrucate pattern. H. Oospore in SEM. i. Oospore wall in SEM with verrucate pattern. Scales: $\mathrm{a}=500 \mu \mathrm{m} ; \mathrm{d}, \mathrm{f}=200 \mu \mathrm{m} ; \mathrm{e}=30 \mu \mathrm{m} ; \mathrm{g}, \mathrm{i}=10 \mu \mathrm{m}$; $\mathrm{h}=50 \mu \mathrm{m}$. 
todo o comprimento do râmulo; dáctilos 2-3, 1-celulados, mucroniformes, 301-620 $\mu \mathrm{m}$ compr., 132-165 $\mu \mathrm{m}$ diâm. Râmulos verticilados férteis 6-7, 1-furcados, dispostos em capítulos, 1110-1338 $\mu$ m compr., 183-218 $\mu \mathrm{m}$ diâm.; dáctilos 2-3, 1-celulados, 527-774 $\mu \mathrm{m}$ compr., 137-209 $\mu \mathrm{m}$ diâm. Capítulos frouxos, 0,2-0,5 cm, terminais ou axilares, 1-3 por verticilo, pedunculados, pedúnculos de tamanhos variados, 2-4 verticilos férteis.

Gametângios conjuntos; glóbulos 215-240 ㅆm diâm., 8 escudos, triangulares; núculas 1-2 por nó, na base dos dáctilos, 203-327 $\mu \mathrm{m}$ compr., 164-241 $\mu \mathrm{m}$ diâm., convolações 7-8, corônula 36-43 $\mu \mathrm{m}$ compr., 39-42 $\mu \mathrm{m}$ diâm., células superiores geralmente $2 \mathrm{x}$ maiores. Oósporo oval, castanho-escuro, 6-7 estrias, 229-273 $\mu \mathrm{m}$ compr., 201$238 \mu \mathrm{m}$ diâm., fossa 31-50 $\mu \mathrm{m}$ larg. Parede do oósporo em MO e MEV com padrão de ornamentação granulosa (Fig. $10 \mathrm{~g}, \mathrm{~h}$ ). Em MEV, a parede exibe grânulos pouco salientes, densamente agregados, algumas vezes fusionados (Fig. 10 i), com 1,5-2,1 $\mu \mathrm{m}$ diâm. Estrias com o mesmo padrão de ornamentação da parede da fossa; rebordo saliente discreto.

Material examinado: BRASIL. BAHIA. Região Metropolitana de Feira de Santana: Amélia Rodrigues: HUEFS 225684.

Habitat: Plantas ocorrendo na margem de lago de fundo areno-lodoso, associadas a Nymphaea sp., Gramineae e Cyperaceae. Condutividade elétrica: $0,19 \mathrm{mS} \mathrm{cm}^{-1}$; oxigênio dissolvido $5,5 \mathrm{mg} \mathrm{L}^{-1}$; $\mathrm{pH} 6,47$; sólidos totais dissolvidos 0,09; temperatura da água $30,8^{\circ} \mathrm{C}$.

Distribuição geográfica no Brasil: São Paulo (VieiraJunior et al. 2002) e Bahia (presente estudo).

Nitella praelonga assemelha-se morfologicamente à $N$. cernua, sendo esta distinta por ser dioica (Bicudo \& Yamaoka 1978, Bueno \& Bicudo 1997, Vieira-Junior et al. 2002, Picelli-Vicentim et al. 2004).

Wood \& Imahori (1965), embora tenham reconhecido essa distinção, consideraram $N$. praelonga como variedade de $N$. cernua, baseados no aparente isolamento geográfico: N. cernua var. cernua, ocorrendo desde a América Central até a América do Sul, e N. cernua var. praelonga, na América do Norte, dos Estados Unidos (Illinois) ao México.

A ocorrência de $N$. praelonga em ambientes lóticos no Estado de São Paulo, citação pioneira para o Brasil documentada por Vieira-Junior et al. (2002), refutou a hipótese de Wood \& Imahori (1965) quanto a separação biogeográfica destas no continente americano.

No presente estudo, observamos que o padrão de ornamentação da parede do oósporo ao MEV foi útil na separação dos táxons, pois $N$. cernua apresentou padrão fibroso e $N$. praelonga, verrucoso. Os dados obtidos para esta última espécie estão sendo documentados pela primeira vez, ao passo que, os de N. cernua estão de acordo John \& Moore (1987) para plantas coletadas em Minas Gerais. Os espécimes analisados concordam com os descritos e ilustrados por Wood \& Imahori (1965) e por Vieira-Junior et al. (2002).

Esse é o primeiro registro de ocorrência da espécie para o Nordeste do país.

\section{Considerações finais}

O presente estudo ampliou a distribuição geográfica de Nitella no Brasil e o conhecimento sobre o gênero na Bahia, que agora apresenta seis táxons registrados: $N$. axillaris, $N$. cernua, $N$. mucronata, $N$. oligospira, $N$. praelonga e $N$. subglomerata.

Os resultados da ornamentação da parede dos oósporos em MEV foram decisivos na delimitação dos táxons com morfologia similares, como $N$. cernua (padrão fibroso) e $N$. praelonga (padrão verrucoso). Segundo John \& Moore (1987), a ornamentação do oósporo em MEV é mais informativa do que outros atributos estruturais (como largura, comprimento, fossa, estrias) dos táxons de Nitella, dado o caráter conservado dessa estrutura (Ray et al. 2001, Urbaniak 2011). Estudos com marcadores moleculares integrados ao da ultraestrutura do oósporo em MEV comprovam que este é filogeneticamente informativo no gênero (Sakayama et al. 2002, 2004a, 2005, Borge \& Necchi 2018).

Devido à representatividade de novos registros para o Estado, recomenda-se a ampliação de estudos taxonômicos na Região Metropolitana de Feira de Santana, tendo em vista que a perda de habitat, gerado pela pressão antrópica em relação às lagoas da região, pode levar à extinção de táxons de Charophyceae, incluindo aqueles que se quer são conhecidos pela ciência.

\section{Agradecimentos}

Este estudo foi parcialmente financiado pela Coordenação de Aperfeiçoamento de Pessoal de Nível Superior - Brasil (CAPES) - Código Financeiro 001. Os autores também agradecem ao Conselho Nacional de Desenvolvimento Científico e Tecnológico (CNPq) e à Fundação de Amparo à Pesquisa do Estado da Bahia (FAPESB) (Projeto "Flora da Bahia", 483909/2012), pelo apoio financeiro; à Maria Aparecida dos Santos, pela ajuda nas coletas do material. A primeira Autora agradece ao CNPq pela Bolsa de Mestrado (Processo No 133387/2015.1).

\section{Conflitos de interesse}

Não há conflito de interesses.

\section{Contribuições dos autores}

Camila dos Anjos Ribeiro: Contribuição para o conceito de estudo; coleta de dados; análise e interpretação de dados; preparação e revisão do manuscrito.

Norma Catarina Bueno: Contribuição na interpretação de dados; preparação e revisão do manuscrito.

João Fernando Prado: Contribuição na interpretação de dados; preparação e revisão do manuscrito.

Geraldo José Peixoto Ramos: Contribuição na coleta de dados; preparação e revisão do manuscrito.

Carlos Wallace do Nascimento Moura: Contribuição para o conceito de estudo; coleta e interpretação de dados; preparação e revisão do manuscrito. 


\section{Literatura citada}

Allen, G.O. 1928. Charophyte notes from Saharanpur, U.P. Journal of the Indian Botanical Society 7: 49-69.

Almeida, J.A.P. 1992. Estudo morfodinâmico do sítio urbano de Feira de Santana. Dissertação de Mestrado, Universidade Federal da Bahia, Salvador.

Bicudo, R.T.M. \& Yamaoka, D.M. 1978. O gênero Nitella (Charophyceae) no Brasil, 1: Subgênero Nitella. Acta Biológica Paranaense 7: 77-98.

Borge, R.G. \& Necchi Jr., O. 2018. Taxonomy and phylogeny of Nitella (Charophyceae, Characeae) from Brazil with emphasis on the midwest and southeast regions. Phytotaxa 356 (3): 181-198

Branco, L.H.Z. \& Necchi-Junior., O. 1998. Distribution of stream macroalgae in three tropical drainage basins. Archiv fur Hydrobiologie 142: 241-256.

Bueno, N.C. \& Bicudo, C.E.M. 1997. Characeae (Charophyceae) do Pantanal do Mato Grosso do Sul, Brasil: Nitella. Hoehnea 24: 29-55.

Bueno, N.C., Prado, J.F., Meurer, T. \& Bicudo, C.E.M. 2011. Novos registros de Nitella (Chlorophyta, Characeae) para regiões dos Estados de Mato Grosso e Mato Grosso do Sul, Brasil. Hoehnea 38: 385-396.

Bueno, N.C., Prado, J.F., Meurer, T. \& Bicudo, C.E.M. 2016. Nitella (Streptophyta, Characeae) from Southern Brazil. Iheringia Série Botanica 71(2): 1-23.

Bueno, N.C. \& Bicudo, C.E.M. 2020. Charophyceae in Flora do Brasil 2020 em construção. Jardim Botânico do Rio de Janeiro. Disponível em <http://floradobrasil.jbrj.gov.br/ reflora/floradobrasil/FB128674 (acesso em 20-X-2020).

Casanova, M.T. 2009. An overview of Nitella (Characeae, Charophyceae) in Australia. Australian Systematic Botany 22: 193-218.

Guiry, M.D. \& Guiry, G.M. 2020. AlgaeBase. World-wide electronic publication, National University of Ireland, Galway. Disponível em http://www.algaebase.org (acesso em 02-X-2020)

John, D.M. \& Moore, J.A. 1987. An SEM study of the oospore of some Nitella species (Chlorophyta, Charales) with descriptions of wall ornamentation and an assessment of its taxonomic importance. Phycologia 26: 334-355.

Mandal, D.K., Ray, S. \& Mukherjee, A. 1995. Scanning electron microscopic study of compound oospore wall ornamentations in some taxa under Nitella furcata complex (Charophyta) from India. Phytomorphology 45: $39-45$

Meurer, T.S. \& Bueno, N.C. 2012. The genera Chara and Nitella (Chlorophyta, Characeae) in the subtropical Itaipu Reservoir, Brazil. Brazilian Journal of Botany 35: 219-232.
Migula, W. 1897. Die Characeen Deutsehlands, Oesterreichs unfl der Schweiz. In: KryptogamenFlora yon Deutschland, Oesterreich und der Schweiz (Rabenhorst, L., Editor), vol. 5, 1-765. E. Kummer, Leipzig.

Necchi-Junior, O., Branco, C.C.Z. \& Branco, L.H.Z. 2000. Distribution of stream macroalgae in São Paulo State, Southeastern Brazil. Algological Studies 97: 43-57.

Necchi Júnior, O., Branco, L.H.Z. \& Spezamiglio, D.N. 2008. Distribuição ecológica de macroalgas de ambientes lóticos do Parque Nacional de Itatiaia (RJ, MG), Brasil. Revista Brasileira de Botânica 31: 135145.

Picelli-Vicentim, M.M. \& Bicudo, C.E.M. 1993. Criptógamos do Parque Estadual das Fontes do Ipiranga, São Paulo, SP. Algas, 4: Charophyceae. Hoehnea 20: 9-22.

Picelli-Vicentim, M.M. 1990. Characeae do Estado de São Paulo: inventário sistemático. Tese de Doutorado, Universidade Estadual Paulista, Rio Claro.

Picelli-Vicentim, M.M., Bicudo, C.E.M. \& Bueno, N.C. 2004. Charophyceae. In: Flora ficológica do Estado de São Paulo (C.E.M. Bicudo, org.). RiMa Editora, São Carlos 4:1-124.

Prado, J.F. 2003. Characeae do Rio Grande do Sul, Brasil. Tese de Doutorado, Universidade Federal do Rio Grande do Sul, Porto Alegre.

Ribeiro, C.R., Ramos, G.J.P., Bueno, N.C., Prado, J.F. \& Moura, C.W.N. 2018. O gênero Chara (Charophyceae, Characeae) das Regiões Metropolitanas de Salvador e de Feira de Santana, Bahia, Brasil. Rodriguésia 69(4): 1987-2017.

Sakayama, H. 2008. Taxonomy of Nitella (Charales, Charophyceae) based on comparative morphology of oospores and multiple DNA marker phylogeny using cultured material. Phycological Research 56:202-15.

Sakayama, H., Nozaki, H., Kasaki, H. \& Hara, Y. 2002. Taxonomic re-examination of Nitella (Charales, Charophyceae) from Japan, based on microscopical studies of oospore wall ornamentation and rbcL gene sequences. Phycologia 41: 397-408.

Sakayama H., Hara Y. \& Nozaki, H. 2004a. Taxonomic re-examination of six species of Nitella (Charales, Charophyceae) from Asia, and phylogenetic relationships within the genus based on rbcL and atpB gene sequences. Phycologia 43: 91-104.

Sakayama, H., Hara, Y., Arai, S., Sato, H. \& Nozaki, H. 2004b. Phylogenetic analyses of Nitella subgenus Tieffallenia (Charales, Charophyceae) using nuclear ribosomal DNA internal transcribed spacer sequences. Phycologia 43: 672-681. 
Sakayama, H., Arai, S., Nozaki, H., Kasai, F. \& Watanabe, M.M. 2006. Morphology, molecular phylogeny and taxonomy of Nitella comptonii (Charales, Characeae). Phycologia 45: 417-21.

Souza, A.S., Silva, L.L., Jesus, T.B., Rodrigues, D.P. \& Santos, L.T.S.O. 2017. Análise Morfométrica das Lagoas de Feira de Santana-BA como Base para a Avaliação da Qualidade da Água. In: D. F. M GHERARDI \& L. E. O. C. ARAGÃO, (ed.) Anais do $18^{\circ}$ Simpósio Brasileiro de Sensoriamento Remoto, Santos, pp. 6858-6865.

Siqueira-Filho, J. \& Bueno, N.C. 2012. A flora das caatingas do rio são Francisco In: J. A. Siqueira-Filho (Org.). Flora das Caatingas do Rio São Francisco. Flora das Caatingas do Rio São Francisco. Rio de janeiro:
Andrea Jakobsson Estúdio Editorial Ltda, 2012, v. 1, pp.445-543

Urbaniak, J. 2009. Oospore variation in Nitella gracilis and Nitella mucronata (Charales, Charophyceae) from Poland. Biologia 64, pp. 252-260

Vieira-Junior, J., Necchi-Junior, O., Branco, C.C.Z. \& Branco, L.H.Z. 2002. Characeae (Chlorophyta) de ecossistemas lóticos do Estado de São Paulo, Brasil, 1: gênero Nitella. Hoehnea 29: 249-266.

Wood, R.D. \& Imahori, K. 1965. A revision of the Characeae, 1: monograph of the Characeae. J. Cramer, Weinhen.

Recebido: 28.10 .2020

Aceito: 04.02.2021

Editor Associado: Carlos Eduardo Wetzel 